\title{
Assessment of Microstructure and Mechanical Properties of Friction Stir Welded AA2014-0 and AA2014-T6 Sheets
}

\author{
Wali Muhammad \\ Institute of Space Technology \\ Wilayat Husain \\ Institute of Space Technology \\ Anjum Tauqir \\ Institute of Space Technology \\ Abdul Wadood \\ Institute of Space Technology \\ Hamid Zaigham \\ Institute of Space Technology \\ Muhammad Atiq Ur Rehman ( $\square$ atique1.1@hotmail.com ) \\ Institute of Biomaterials https://orcid.org/0000-0001-5201-973X
}

\section{Research Article}

Keywords: AA2014, temper conditions, friction stir welding, microstructure, tensile strength, microhardness, fracture location

Posted Date: March 1st, 2021

DOI: https://doi.org/10.21203/rs.3.rs-256613/v1

License: (c) (1) This work is licensed under a Creative Commons Attribution 4.0 International License. Read Full License 


\section{Abstract}

In this study, friction stir welding of AA2014-0 and AA2014-T6 aluminum alloy was performed at various welding speeds to evaluate the influence of temper conditions of base metal on the properties of the welded joints. The results showed strong influence of base metal temper conditions on the microstructural morphologies and mechanical behavior of the welded joints. In the 2014-0 joints, different zones of weld joint were diffused into each other and there was no clear interface between them. In 2014-T6 joints, there was a distinct demarcation between the NZ, TMAZ, HAZ and base metal. The welded joints in 2014-0 temper condition showed increase in hardness in the vicinity of weld center due to grain refinement whereas, in 2014-T6, softening occurred in the same region by the dissolution of strengthening precipitates. The mechanical properties of 2014-0 joints were equivalent to the base metal showing a $100 \%$ weld efficiency with fracture located in the base metal, whereas 2014-T6 welds exhibited about $70 \%$ weld efficiency with fracture located at the NZ/TMAZ interface. All the samples in mechanical testing fractured at retreating side (RS) which exhibited heterogeneity in the mechanical properties of the welded joints. SEM fractographic analysis revealed a ductile fracture mode comprising of dimples in both temper conditions. The size and shape of the dimples was strongly dependent on base metal temper condition.

\section{Introduction}

The heat treatable aluminum alloys of 2xxx series are the key alloys used in structures where the key design benchmark is high specific strength, good fracture toughness and damage tolerance such as aerospace, marine, petrochemical, power generation and transport industries [1-4]. The weldability of AA2xxx aluminum alloys, by conventional fusion methods, is poor due to the formation of hot cracks, undesirable microstructure and porosity. However, newly developed Friction Stir Welding method can join metal alloys that are considered unsuitable for welding via conventional fusion joining methods [5]. The process is being progressively practiced for welding of similar as well as dissimilar metals with ease. This technique also has the benefit of being solid-state, which alleviates the need for liquid filler metals that are common with conventional fusion welding techniques [6, 7]. Friction stir welding involves a rotating non-consumable tool of harder than base metal material. The tool generates sufficient heat, by friction and plastic strain, to soften the base material without melting. The friction occurs between the tool shoulder and upper surface of the sheets whereas plastic strain takes place by the rotating pin of the tool. These thermo-mechanical conditions result in diverse microstructures in the weld region. The transverse section of the weld joint shows a region of severe deformation and material flow and is known as nugget zone (NZ) [8]. The microstructure of this zone consists of very fine equiaxed grains having high angle grain boundaries. The temperature in the NZ may reach upto $0.95 T_{m}[9]\left(T_{m}\right.$ is the melting temperature of the material) and thus is high enough to completely or partially dissolve the strengthening precipitates $[8,10,11]$. The region next to NZ is called thermomechanically affected zone (TMAZ). This zone does not experience the direct action of pin or shoulder. However, it is subjected to severe thermomechanical fluctuations due to internal shear stresses. The strengthening precipitates are coarsened in 
this region due to plastic deformation and high temperature resulting in decrease in hardness $[8,12]$. The region between the TMAZ and base metal (BM) is known as heat affected zone (HAZ). Due to the dissolution or coarsening of strengthening precipitates, this region shows a significant decrease in hardness [8] as compared to the BM. Many studies have focused on the mechanical properties of friction stir welded precipitation hardenable aluminum alloys of 2xxx series. Yu et al [13] observed that tensile and yield strength decreased while ductility was increased in the nugget zone of the friction stir welded 2198-T8 alloy due to softening in the welded region. Meshram et al [14] studied the effect of tool pin profile and welding speed on the quality of weld joints in AA2014-T6 plates. Aydin et al [15] observed that welding parameters strongly affect the mechanical and fatigue properties of the friction stir welded AA2014-T6 alloy. The effects of welding parameters on FSW characteristics, such as microstructural morphologies in joints e.g. Ramanjaneyulu et al [16] observed that microstructure of friction stir welded AA2014-T6 is governed by the tool pin profile and welding parameters which in turn influences the mechanical properties of the joint. Norman et al [17] studied the grain structure of friction stir welded joints of 2024-T351 alloy with the help of high resolution electron back scattered diffractrography (EBSD) technique. They concluded that different local deformation conditions and high strain rates result in different stages of dynamically recrystallized grains structures. Similar observations were made by Jones et al [18] in friction stir welded 2024-T351 alloy. Zhang et al [19] found that anisotropy in microstructure of friction stir welded 2024-T3 was responsible of difference in mechanical properties. Material flow behavior in the welds has also been addressed by many researchers such as Huaxia et al [20] studied the material flow behavior of friction stir welded 2024-T351 with the help of thin copper strips. They observed that at different welding parameters the material fragmentation and dispersion is decreased at high heat inputs and vice versa. It was explained in terms of base material softening and shear stresses. Li et al [21] studied the material flow behavior in during refill friction stir spot welding of alclad 2A12-T4 alloy and found that plasticized material flow was due to extrusion and shearing actions. Qin et al [22] studied experimentally and numerically the material flow behavior in high speed friction stir welded joints of 2024 sheets. They concluded that at high rotation speeds, flow velocities were high and it decreases with increasing distance from the weld center. Residual stress analysis in the friction stir welded joints has also been a subject of many investigations. Li et al [23] carried out experimental and numerical investigation of residual stresses in friction stir welded 2024-T4 alloy and observed that due to the tool force the longitudinal residual tensile stresses became smaller and were non-uniformly distributed at different sides of the weld center. Fratini et al [24], in their work of effect of longitudinal residual stresses on fatigue crack growth in friction stir welded 2024-T351 concluded that fatigue crack growth rate was controlled by residual stresses outside the weld zone and microstructure and hardness are the controlling factors within the weld zone. Delijaicov et al [25] showed that tool rotation speed and welding speed were the controlling factors for residual stresses during the friction stir welding of dissimilar butt joint of AA2024-T3 and AA7475-T761. Although, there are a few studies concerning the effects of base material temper conditions on the properties of friction stir welding of 2xxx series aluminum alloys, they are mainly focused on more commercial, AA2024 and AA2219, alloys. The research work related to friction stir welding of AA 2014 alloy is mostly focused on T6-tempered condition and the comparative studies of weld characteristics and joint performance in different heat treatment conditions of base metal are not 
available. In the present investigation, AA2014 aluminum alloy sheets were friction stir welded in two different heat treatment states i.e. annealed ' $O$ ' and age-hardened ' $T 6$ ' conditions to evaluate the influence of different temper conditions of the base metal on microstructural morphologies, strength and fracture characteristics. A comprehensive assessment of microstructural development, strength and hardness in the weld zone of the joints is also made between the ' $O$ ' and 'T6' temper conditions.

\section{Materials And Experimental Method}

The material used in this study was commercially available $2.5 \mathrm{~mm}$ thick, rolled sheets of AA2014 alloy. The chemical composition and mechanical properties of the materials used in this study are given in Tables 1 and 2, respectively.

Table 1

Chemical composition of the sheet material, wt.\%

\begin{tabular}{|llllll|}
\hline Al & Cu & Mg & Mn & Fe & Si \\
\hline Balance & 3.8 & 0.52 & 0.57 & 0.12 & 0.84 \\
\hline
\end{tabular}

Table 2

Mechanical Properties of 2014-0 and 2014-T6 sheets samples

\begin{tabular}{|lllll|}
\hline Sample ID & UTS, (MPa) & YS, (MPa) & Elongation, \% & Hardness (HV) \\
\hline AA2014-0 & 189 & 92 & 17 & $52 \pm 2$ \\
\hline AA2014-T6 & 499 & 441 & 15 & $157 \pm 3$ \\
\hline
\end{tabular}

The blanks of $250 \times 80 \times 2.5 \mathrm{~mm}$ dimension were cut from the sheet by shear cutter. A set of pieces was then subjected to $\mathrm{T} 6$ treatment by solutionizing at $510^{\circ} \mathrm{C}$ followed by warm water quenching. Artificial Aging was then performed at $170^{\circ} \mathrm{C}$ for 16 hours in an electric oven. In order to get smooth and parallel faying edges, the sheared edges were milled on a milling machine. The edges were rubbed by emery paper just before welding to remove surface oxides followed by cleaning with a suitable solvent to wipe out dirt, debris and oil remnants. The friction stir welding was carried out on a computer-controlled vertical milling machine. The tool used was made of hardened and tempered $\mathrm{H} 13$ tool steel having an eccentric grooved shoulder of $\phi 10 \mathrm{~mm}$ and a threaded taper pin of $\phi 4 \mathrm{~mm}$ with a length of $2.25 \mathrm{~mm}$. The welding parameters used in this study are given in Table 3 . The tool rotation speed and tool tilt angle was kept the same for welds and only the tool travel speed was varied. All the welds were in butt joint configuration. The welding, of equal lengths of $200 \mathrm{~mm}$, was done in a single pass, perpendicular to the rolling direction of the sheet along the long edges of the blanks. A physical picture and schematic diagram [26] of the welding setup is shown in Fig. 1(a,b). 
Table 3

Parameters used for friction stir welding of AA2014 sheets

\begin{tabular}{|llll|}
\hline Rotation speed, $(\mathrm{rpm})$ & Travel speed, $(\mathrm{mm} / \mathrm{min})$ & Tilt angle, $\left.\mathbf{(}^{\circ}\right)$ & Joint ID \\
\hline 600 & 2 & 120 \\
\cline { 2 - 2 } & 200 & 200 \\
& 280 & 280 \\
\hline
\end{tabular}

After welding, the samples for metallographic analysis and hardness measurement were extracted from the joints by cutting across the welding direction. Proper care was taken to avoid any artifacts during the cutting process.

For microstructural analyses, the cross-sections of the joints were mounted and then polished according to the standard sample preparation procedure and then etched with Keller's reagent [27] to reveal the microstructure. The samples were then observed under optical microscope in the bright field mode.

Microhardness profiles of the joints were determined with a Vickers micro-hardness testing machine at $100 \mathrm{~g}$ load applied for 10 seconds. The measurements were made at mid-thickness, transverse to the welding direction, keeping a distance of $0.25 \mathrm{~mm}$ between the adjacent indents. The measurements were made starting from the base material (BM) to heat affected zone (HAZ), the thermomechanically affected zone (TMAZ), the nugget zone (NZ) from retreating side (RS) up to the advancing side (AS).

Tensile test samples, for the determination of mechanical properties, with $25 \mathrm{~mm}$ gage length, were cut across the welding direction with the help of EDM-wire cutting machine according to ASTM E08 [28] according to the dimensions shown in Fig. 2. All the samples were uniaxially tested, at a universal tensile testing machine equipped with high resolution extensometers. Tests were performed at room temperature and at a crosshead speed of $1 \mathrm{~mm} / \mathrm{min}$. At least three samples were tested for each condition to maintain the reliability of the tensile test results. After the tensile test, fracture surfaces of the samples were secured for SEM fractographic examination.

\section{Results And Discussion}

\subsection{Microstructural Morphologies}

The macrographs of 2014-0 and 2014-T6 welds, at different welding parameters, are shown in Fig. 3 and Fig. 4, respectively. All the macrographs are taken at 20x magnification. The advancing and retreating sides of the joint are indicated by 'AS' and 'RS' respectively. The typical four regions of the friction stir welded joint are also labeled as NZ, TMAZ, HAZ and BM. From the figures it is clearly observed that the joints in both temper conditions have very different microstructural morphologies. Figure 3 shows 2014-0 joints welded at different welding speeds. It is seen that the weld nuggets have partial 'onion rings' 
features in all the three welds. The fraction of these features reduces as the welding speed is increased. On the other hand, in 2014-T6 joints, Fig. 4, the 'onion rings' features are present in greater amount over the entire width of the NZ. The presence of 'onion rings' like features shows that the joints experienced sufficient plastic flow during welding process and the plasticized material was deposited in multiple layers [29]. It was observed by Sutton et al that 'onion ring' like features are due to the banded microstructure. These bands are formed due to uneven distribution of hard particles [30]. In 2014-0 base material, majority of the precipitates exist in stable state and a relatively less fraction of metastable precipitates is present in the material in the form of $\mathrm{Al}_{2} \mathrm{Cu}, \mathrm{AlCuMn}$ and $\mathrm{AlCuMg}$ [31]. At low welding speed, the peak temperature during FSW is high enough to dissolve and solutionize some fraction of the metastable particles into the aluminum matrix. However, the large amount of stable precipitates remains unaffected and are accumulated in high-strain regions giving rise to formation of bands of low and high particle density [30]. These bands give rise to partial 'onion rings' morphology in the NZ of 2014-0 on advancing side. It is worth noting that, as the welding speed in increased, the peak temperature is reduced and hence the proportion of 'onion rings' features also reduces, Fig. 3(c).

For 2014-T6 base material, the majority of the precipitates exist in the metastable state and only a small fraction of stable precipitates is present in the material. During FSW process an appreciable amount of these metastable precipitates is dissolved in the aluminum matrix. As discussed above, the stable precipitates remain unaffected and are segregated in high strain regions, resulting in the formation of high and low particle density bands in the NZ. Such bands appear as 'onion rings' features in the NZ of 2014-T6 joints.

From Figs. 1 and 2 it can also be observed that in 2014-0 joints, the size of weld bead remains almost the same at different welding speeds. However, in case of 2014-T6 joints, there is a marked effect of welding speed on the dimensions of weld bead as it significantly reduces with the increase of welding speed. This reduction in weld size is due to lesser amount of material flow around the rotating pin at high welding speed. Same observations were made by Venkateswarlu et. al. in their study on 2219-T62 and 2219-T87 alloys [32].

The optical micrographs of base metals (BM) in ' $O$ ' and 'T6' conditions are shown in Fig. 5 . The microstructure represents typical features of a rolled material consisting of elongated grains oriented along the rolling direction consisting of fine $\mathrm{Al}_{2} \mathrm{Cu}$ precipitates, distributed in the $\mathrm{a}-\mathrm{Al}$ matrix and dark colored particles. These particles are generally $\mathrm{Al}_{2} \mathrm{CuMg}$ and $(\mathrm{Cu}, \mathrm{Fe}, \mathrm{Mn}) \mathrm{Al}_{6}$ or $\mathrm{Al}_{7} \mathrm{Cu}_{2} \mathrm{Fe}$ [33]. The average grain size of 2014-0 and 2014-T6 BM was $19.7 \mu \mathrm{m}$ and $27 \mu \mathrm{m}$, respectively.

The NZ microstructures of 2014-0 and 2014-T6 joints are presented in Fig. 6. It was observed that the grain size in the NZ of 2014-0 is coarser than 2014-T6. This may be attributed to the difference in their temper conditions which can significantly affect the mechanism of recrystallization. However, it was in contradiction to the observations made by Venkateswarlu et al in 2219-0 and 2219-T6 aluminum alloys, where grain size of NZ was large in T6 alloys than the 0 alloys [34]. This may also be ascribed to the difference in hardness of both the materials. As 2014-0 has much lower hardness than 2014-T6 samples, 
the mechanical agitation and subsequent material flow and temperature rise will be more severe in 20140 than in 2014-T6 leading to coarsening of recrystallized grains during cooling from weld temperature to room temperature in the former than in the latter. The microstructure in both temper states consists of recrystallized fine-equiaxed grains in the NZ. This can be explained in terms of rotation and linear motion of tool during FSW process which causes severe plastic deformation by tool pin and high thermal effects by tool shoulder, resulting in the semi-solid material in this region. This semi-solid material forcefully flows along the tool pin surface of the rotating tool causing severe shear strains. Due to severe plastic strains at elevated temperature, dynamically recrystallized grains are nucleated at the grain boundaries of initially large and elongated grains in the NZ [35,36]. The same trend was found in 2014-0 and 2014-T6 samples welded at different welding speeds.

The microstructural variation from NZ to TMAZ are presented in Figs. 7 and 8 for 2014-0 and 2014-T6 joints, respectively. In 2014-0 joints, the boundary between NZ and TMAZ is not clear on the RS (Fig. 7a) whereas a narrow band of transition of grains from NZ to TMAZ was observed on AS (Fig. 7b). The same trend was also observed in other 2014-0 samples which were welded at travel speeds of 200 and 280 $\mathrm{mm} / \mathrm{min}$. However, 2014-T6 joints showed a very distinct transition interface between the NZ and TMAZ on RS as well as AS irrespective of the travel speed. The same phenomena have been observed by other workers $[9,37,38]$ and is explained in terms of the difference in plastic flow of material on advancing and retreating sides of a weld. The interface is more distinct on the side having higher shear forces and plastic strains. Since on AS, the directions of tool travel and plastic deformation are in the same direction, the shear forces and plastic strains are higher on this side, resulting in clear interfaces between NZ and TMAZ.

The region of TMAZ experiences both high temperature and plastic deformation to lesser extent than the NZ. The combined effect of deformation and temperature results in a microstructure which consists of elongated and rotated grains. The recrystallization mainly begins at NZ/TMAZ interface. The grain size of TMAZ is much larger than the NZ. Due to the thermal effects, the strengthening precipitates grow and get overaged thus causing drop in hardness in this region [35].

Figure 9 shows the HAZ in 2014-0 and 2014-T6 samples. The size of HAZ in 2014-T6 is relatively larger than 2014-0. In both cases, there is no discernable boundary between HAZ and the base metal because the microstructural transition is not significant. HAZ experiences only thermal fluctuations and no plastic deformation takes place in this region. As a result, the grains are not recrystallized and the grain size is similar to or slightly larger than the base metal. Due to the thermal effects, hardening precipitates can dissolve or coarsen resulting in reduction of hardness. The extent of precipitate dissolution and coarsening depends on the base material condition.

\subsection{Microhardness of the joints}

Microhardness test were conducted on the transverse cross-sections of the weld joints. The microhardness profiles of 2014-0 and 2014-T6 joints, welded at different welding parameters, are presented in Figs. 10 and 11 respectively. In 2014-0 temper condition, the hardness is increased in the 
welded region with respect to BM whereas, and in 2014-T6 temper condition, it is decreased as compared to the BM. This may be ascribed to the difference in their BM temper conditions. The BM in 2014-0 condition is mainly composed of a-Al grains in which precipitates are not dispersed homogeneously. Whereas, BM in 2014-T6 condition consists of a-Al grains with thoroughly distributed fine strengthening precipitates [39]. From the hardness profiles in Fig. 8, it can be observed that hardness increases in all 2014-0 joints, irrespective of the welding parameters used. Also the increase in hardness is almost the same in all cases. Same observations were also made by [40-42] in different friction stir welded aluminum alloys. This increase in hardness in ' $O$ ' temper condition is due to the fact that the grain refinement took place in the weld region especially in the NZ, thus giving rise to hardness in this region. Since the temperature is high enough there may be some precipitation of strengthening particles during cooling from high temperature to room temperature $[43,44]$. It was also observed that the rise in hardness did not vary significantly with change in welding speed.

A decrease in hardness occurred in weld zone of all the samples in 2014-T6 condition as opposed to 2014-0 samples. It was due to the fact that high temperature and severe plastic strains dissolved the hardening precipitates back into the a-Al matrix of NZ. The samples in 2014-T6 condition showed a typical 'W' shaped profile across the welded region, Fig. 11. The partial recovery in hardness of NZ is due to grain refinement and re-precipitation of hardening phases during cooling from welding temperature to room temperature $[43,44]$. The loss in hardness was maximum in the TMAZ and HAZ which was due to dissolution and coarsening of hardening precipitates and grain growth $[45,46]$. The hardness loss was not same for all the samples of 2014-T6 condition at different welding parameters. The samples welded at low travel speed $(120 \mathrm{~mm} / \mathrm{min})$ showed a maximum loss in hardness by giving a value of minimum hardness of $85 \mathrm{HV}$, whereas, the samples welded at high travel speed $(280 \mathrm{~mm} / \mathrm{min})$ showed a minimum hardness upto $92 \mathrm{HV}$. This may be caused by high thermal fluxes at low travel speed resulting in greater volume of precipitate dissolution than at high travel speed where low thermal effects dissolved lesser amount of the hardening precipitates. Same interpretations were made by other researchers in FSW of different aluminum alloys [34, 35].

\subsection{Mechanical properties of the joints}

The mechanical properties of the 2014-0 and 2014-T6 joints, welded at different welding parameters, are presented graphically in Figs. 12 and 13, respectively, alongwith the BM properties. The yield strength, ultimate tensile strength, percentage elongation and percentage of joint efficiencies of and the BM properties are also summarized in Table 4 for comparison.

From Fig. 12, it is evident that the yield strength and ultimate tensile strength of 2014-0 joints were almost same as that of BM, however, the joints showed about 15\% drop in elongation. Thus the joint efficiency was $100 \%$ as shown in Table 4 . The decrease in elongation is due to the high hardness in the NZ, Fig. 10. During tensile test, the load concentrates more in the low hardness region of the joint and final fracture takes place in this region [45]. For 2014-0 joints the low hardness region is base metal, see Fig. 10. Therefore, NZ offered greater resistance to plastic deformation during tensile test, thus reducing 
the overall elongation. Similar observations have been made by other researchers in friction stir welded 6061-0 and 7075-0 alloys [45, 46].

The tensile samples of 2014-T6 condition showed different mechanical behavior as compared to 2014-0 samples. The mechanical properties of the 2014-T6 joints were lower than the base metal as illustrated in Fig. 13. The mechanical properties of the friction stir welded joints are determined by welding defects and the hardness distribution across the weld joint [35]. In a defect free joint, hardness profile across the weld mainly controls the mechanical properties. It is also known that the friction stir welded joint consists of a non-uniform microstructure with different zones alongwith their interfaces, all of which have different mechanical properties $[9,47]$. From Fig. 11, it can be noted that 2014-T6 joints have low hardness regions, such as NZ, TMAZs and HAZs as compared to BM. The mechanical properties of these regions are lower than the base metal. As discussed earlier, the stress is concentrated in these regions during the tensile test and the joints show lower mechanical properties than the BM. The 2014-T6 joints also showed a remarkable loss in ductility, Table 4. This may be due to the excessive loss of hardness in the weld region. During tensile test the load is confined to this region and major portion of plastic deformation takes place within weld region while BM remains almost intact due to higher hardness. Similar observations were also made in other friction stir welded aluminum alloys $[35,45,46]$.

The yield strength efficiency (YSE), ultimate tensile strength efficiency (UTSE) and elongation efficiency (EE) for 2014-O and 2014-T6 joints are summarized in Table 4. The YSE and UTSE and EE are the ratios of the average yield strength, ultimate tensile strength and elongation of the joints, respectively, to those of the BMs [29]. It can be observed that efficiencies of different mechanical properties strongly depend on BM condition. The 2014-O BM has a complete stable condition and the YS and UTS efficiencies of 2014$O$ joints are almost same as that of BM irrespective of the welding parameter used. However, the EE is lower than BM, being $90 \%$ at low welding speed and $85 \%$ at high welding speed. In 2014-T6, the joints showed much lower weld efficiencies than the BM. The YSE remained around $50 \%$ of BM, whereas UTSE was around $70 \%$ of the BM. The EE in heat treated condition reduced significantly, being $50 \%$ at low welding speed and $32 \%$ at high welding speed. In general, it was observed that the strength and elongation efficiencies are decreased when the stability for precipitation of the BM decreases [35]. 
Table 4

Tensile properties of the base metals and the welded joints

\begin{tabular}{|c|c|c|c|c|c|c|}
\hline \multirow[t]{2}{*}{ Joint ID } & \multicolumn{3}{|l|}{$2014-0$} & \multicolumn{3}{|c|}{ 2014-T6 } \\
\hline & Value* & Std. Dev. & Efficiency, \% & Value & Std. Dev. & Efficiency, \% \\
\hline \multicolumn{7}{|l|}{ BM } \\
\hline - YS [MPa] & 92 & 1 & - & 441 & 3 & - \\
\hline - UTS [MPa] & 189 & 1 & - & 495 & 5 & - \\
\hline - Elongation [\%] & 17 & 2 & - & 15 & 1 & - \\
\hline \multicolumn{7}{|l|}{120} \\
\hline • YS [MPa] & 90 & 3 & 98 & 220 & 2 & 50 \\
\hline • UTS [MPa] & 194 & 3 & 103 & 345 & 4 & 70 \\
\hline - Elongation [\%] & 15 & 2 & 86 & 8 & 1 & 50 \\
\hline \multicolumn{7}{|l|}{200} \\
\hline • YS [MPa] & 86 & 3 & 93 & 237 & 2 & 54 \\
\hline • UTS [MPa] & 179 & 2 & 95 & 359 & 5 & 72 \\
\hline - Elongation [\%] & 15 & 3 & 90 & 6 & 2 & 42 \\
\hline \multicolumn{7}{|l|}{280} \\
\hline • YS [MPa] & 85 & 7 & 92 & 242 & 7 & 55 \\
\hline • UTS [MPa] & 186 & 4 & 98 & 359 & 3 & 73 \\
\hline - Elongation [\%] & 14 & 1 & 85 & 5 & 0.4 & 32 \\
\hline
\end{tabular}

\subsection{Fracture locations and fracture surfaces of the joints}

The analysis of fracture locations and fracture surfaces was carried out to understand the mechanical behavior of 2014-0 and 2014-T6 welded joints. The fracture location represents the weakest region of the joint. Analysis of fractured tensile samples provides useful information about structure-property relationship [33]. From the Table 5, which shows the representative fracture locations of 200 samples, it can be seen that 2014-0 and 2014-T6 have different fracture locations. Same fracture locations were observed in other samples of a group whatever the welding parameters were used. All the tensile samples in ' $O$ ' condition fractured in the BM at RS of the weld joint, Table 4. Since BM had lowest hardness for 2014-0 joints, Fig. 10, all the stress concentration occurred in BM. 


\begin{tabular}{|c|c|c|c|}
\hline S. No & Joint condition & Fractured sample & Fracture location \\
\hline 1 & $2014-\mathrm{O}$ & (x) -1 & $\mathrm{BM}$ \\
\hline 2 & 2014-T6 & it & NZ/TMAZ \\
\hline
\end{tabular}

In 2014-T6 samples, the fracture occurred on RS at NZ/TMAZ interface because it was the weakest region of the weld with minimum hardness, Fig. 11. At the same time, there was drastic variation of microstructure at NZ/TMAZ interface. The TMAZ in these samples has twisted coarse grained microstructure as compared to NZ and HAZ with partially dissolved and coarsened strengthening particles. This significant difference in the internal structure gave rise to the weakest region in the weld joint. Due to low hardness and distinct microstructure, the stress was concentrated in this region during the tensile test.

SEM fractographic analysis has been carried out to understand the mechanism of fracture in the samples. The SEM fractograph of the fracture surface of the 2014-0 tensile sample is shown in Fig. 14. Since all the samples, welded at different welding parameters, fractured from BM, only a representative fractograph of 200 sample is shown here. The fracture surface of 2014-0 joints revealed a typical ductile fracture consisting of deep dimples, of varying size and shape, which result from microvoid nucleation and coalescence. The size of the dimples shows that appreciable plastic deformation took place in the BM which led to deep dimples and high ductility. The notable necking in the vicinity of fracture also supports this observation. Within the dimples, different particles were also observed. Hence it can be stated that samples in ' $O$ ' condition fractured by the microvoid coalescence at coarse constituent particles [48].

Figure 15 shows the SEM fractographs of fractured samples in 2014-T6 condition at different welding parameters. Since fracture in 'T6' condition always occur in weld zone, all the fractographs show a different morphology than the BM. The fracture surfaces show a fine grain size that become finer at high welding speed, Fig. 15 (c). Although the fracture surfaces represent a ductile fracture morphology, yet the dimple size was much finer and shallower than the 2014-0 samples which shows less plastic deformation during loading and a low ductility [35]. This observation is in agreement with the elongation data given in Table 4.

\section{Conclusions}

Following conclusions can be drawn from the analysis of results of the friction stir welded 2014 alloy in different heat treatment conditions:

- The microstructural morphologies of the friction stir welded joints of AA2014 strongly depend on BM temper conditions. 
- The hardness of the 2014-0 joints increased than BM due to grain refinement strengthening, whereas it decreased in 2014-T6 joints due to dissolution of strengthening precipitates.

- The mechanical properties of friction stir welded joints were compatible to BM in 2014-0 temper. However, 2014-T6 showed lower properties than the BM due to partial loss of precipitation hardening effect.

- The elongations of all the samples in both temper conditions were lower than BMs irrespective of the welding parameters.

- BM temper condition strongly influenced the tensile fracture location. The fracture in 2014-0 joints occurred in BM being the lower hardness region whereas in 2014-T6 joints fracture location was at the interface of NZ and TMAZ on the RS.

- The joint strength efficiencies were $100 \%$ for $2014-0$ joints, however, for 2014-T6 condition it was around $70 \%$. The elongation efficiencies showed that ductility was reduced in all cases, the loss was more prominent in T6-temper condition.

- SEM fractographic analysis of fracture surfaces revealed dimples of varying sizes representing ductile mode of failure in both temper conditions. The dimples were representative of ductility of the joint being deep in ' $\mathrm{O}$ ' condition and shallow in 'T6' condition.

\section{Declarations}

\section{Acknowledgements}

The authors acknowledge the technical support provided by Mr. Talha Ahmed, Mr. Muhammad Shahbaz and Mr. Aamir Siddique in FSW. They are also grateful to Mr. Munir Ahmed for assistance in optical and hardness sample preparation, Mr. Muhammad Israr for tensile testing and Mr. Muhammad Tahir Khan for SEM analysis.

\section{Authors Contributions}

The authors' contributions are as follows: Wali Muhammad conceptualized, planned and carried out the experiments. Muhammad Atiq ur Rahman contributed to the analysis and interpretation of results. Abdul Wadood and Hamid Zaigham validated, prepared and edited the original draft. Wilayat Husain and Anjum Tauqir supervised and critically reviewed the research and manuscript. All the authors provided valuable feedback and helped to shape the project, analysis and the manuscript.

\section{Ethics declarations}

\section{Conflict of interest}

The authors declare that they have no conflict of interest.

\section{Ethics approval}


All authors confirm that they follow all ethical guidelines. All authors certify that they have no affiliations with or involvement in any organization or entity with any financial interest or non-financial interest in the subject matter or materials discussed in this manuscript.

\section{Consent to participate}

The authors agree with the participation.

\section{Consent for publication}

The authors agree with the publication.

\section{Code availability}

Not applicable.

\section{Funding}

This research work is partially funded by the Institute of Space technology Islamabad, Pakistan.

\section{Availability of data and materials}

The data presented and/or analyzed during the current study are available from the corresponding author on request.

\section{References}

1. Dursun T, Soutis C (2014) Recent developments in advanced aircraft aluminium alloys. Materials Design 56:862-871. 10.1016/j.matdes.2013.12.002

2. Alloying: Understanding the Basics Ed. J.R. Davis, 2001, ASM International® Materials Park, Ohio, ISBN: 0-87170-744-6

3. Advances in Friction Stir Welding and Processing, Mohammad Kazem Besharati Givi and Parviz Asadi, 2014, Woodhead Publishing, UK, ISBN 978-0-85709-454-4

4. Friction Stir Welding and Processing, Mishra RS, Partha Sarathi De Nilesh Kumar, 2014, Springer, ISBN 978-3-319-07042-1

5. Thomas WM, Nicholas ED, Needham JC, Church MG, Temple-smith P, Smith CJ, International patent application PCT/GB92/02203 and GB patent application no. 9125978.9:1991

6. Biro A, Chenelle B, Lados D (2012) Processing, Microstructure, and Residual Stress Effects on Strength and Fatigue Crack Growth Properties in Friction Stir Welding: A Review. Metallurgical Materials Transactions B 43. 10.1007/s11663-012-9716-5

7. Li H, Gao J, Li Q (2018) Fatigue of Friction Stir Welded Aluminum Alloy Joints: A Review. Applied Sciences 8 2626. 10.3390/app8122626 
8. Lockwood W, Tomaz B, Reynolds AP (2002) Mechanical response of friction stir welded AA2024: Experiment and modeling. Materials Science Engineering: A 323:348-353. 10.1016/S09215093(01)01385-5

9. Orłowska M, Olejnik L, Pietras A, Rosochowski A, Bazarnik, Piotr, Golinski, Jacek, Brynk, Tomasz, Lewandowska, Małgorzata (2015) Microstructure and mechanical properties of friction stir welded joints made from ultrafine grained aluminium 1050. Materials Design 88.

10.1016/j.matdes.2015.08.129

10. Abbasi M, Bagheri B, Keivani R (2015) Thermal analysis of friction stir welding process and investigation into affective parameters using simulation. Journal of Mechanical Science Technology 29:861-866. 10.1007/s12206-015-0149-3

11. Sato Y, Urata M, Kokawa H (2002) Parameters Controlling Microstructure and Hardness during Friction-Stir Welding of Precipitation-Hardenable Aluminum Alloy 6063. Metallurgical Materials Transactions A 33:625-635. 10.1007/s11661-002-0124-3

12. Sato Y, Kokawa H (2001) Distribution of Tensile Property and Microstructure in Frction Stir Weld of 6063 Aluminum. Metallurgical Materials Transactions A 32:3023-3031. 10.1007/s11661-001-01778

13. Ma Yu, Zhenqiang Z, Liu BaoQi, li W (2013) Mechanical properties and fatigue crack growth rates in friction stir welded nugget of 2198-T8 Al-Li alloy joints. Materials Science Engineering: A 569:4147. 10.1016/j.msea.2013.01.044

14. Meshram S, Reddy G, Rao A (2016) Role of Threaded Tool Pin Profile and Rotational Speed on Generation of Defect Free Friction Stir AA 2014 Aluminium Alloy Welds. Defence Science Journal 66:57. 10.14429/dsj.66.8566

15. Aydin H, Tutar M, Durmuş A, Bayram A, Sayaca T (2011) Effect of Welding Parameters on Tensile Properties and Fatigue Behavior of Friction Stir Welded 2014-T6 Aluminum Alloy. Transactions of the Indian Institute of Metals 65. 10.1007/s12666-011-0069-6

16. Ramanjaneyulu K, Reddy GM, Rao AV, Markandeya R (2013) Structure-Property Correlation of AA2014 Friction Stir Welds: Role of Tool Pin Profile. J Mater Eng Perform 22:2224-2240

17. Norman A, Brough I, Prangnell P (2000) High Resolution EBSD Analysis of the Grain Structure in an AA2024 Friction Stir Weld. Materials Science Forum - MATER SCI FORUM. 331-337. 1713-1718. 10.4028/www.scientific.net/MSF.331-337.1713

18. Jones MJ, Heurtier P, Desrayaud C, Montheillet F, Alléhaux, Delphine, Driver, Julian (2005) Correlation between microstructure and microhardness in a friction stir welded 2024 aluminium alloy. Scripta Materialia 52:693-697. 10.1016/j.scriptamat.2004.12.027

19. Zhang Z, li W, Li J, Chao YJ, Vairis A (2015) Microstructure and anisotropic mechanical behavior of friction stir welded AA2024 alloy sheets. Materials Characterization 107:112-118.

10.1016/j.matchar.2015.06.039

20. Huaxia Z, Chunlin D, Guohong L (2011) Material flow behaviour of 2024-T351 aluminium alloys friction stir welding. 1-4. 10.1049/cp.2011.1048 
21. Li Gao-hui, Zhou L, Luo Ling-yun, Wu Xi-ming, Guo N, Material flow behavior and microstructure evolution during refill friction stir spot welding of alclad 2A12-T4 aluminum alloy, Int. J. Miner. Metall. Mater. https://doi.org/10.1007/s12613-020-1998-z

22. Qin D, Fu L, Shen Z (2019) Visualisation and numerical simulation of material flow behaviour during high-speed FSW process of 2024 aluminium alloy thin plate. Int J Adv Manuf Technol. $10.1007 /$ s00170-018-03241-5

23. Li T, Shi Qing-yu, Li H-K (2007) Residual stresses simulation for friction stir welded joint. Science Technology of Welding Joining 12:664-670. 10.1179/174329307X236832

24. Fratini L, Pasta S, Reynolds AP (2009) Fatigue crack growth in 2024-T351 friction stir welded joints: Longitudinal residual stress and microstructural effects. International Journal of Fatigue 31:495500. 10.1016/j.ijfatigue.2008.05.004

25. Delijaicov S, Silva PA, Resende HB, Batalha MH (2018) Effect of Weld Parameters on Residual Stress, Hardness and Microstructure of Dissimilar AA2024-T3 and AA7475-T761 Friction Stir Welded Joints. Materials Research-ibero-american Journal of Materials, 21

26. Nadikudi BK, Kumar A, Davidson M (2011) A review of friction stir welding of AA6061 aluminium alloy. ARPN Journal of Engineering Applied Sciences 6:61-63., N. Bhanodaya Kiran Babu, A. Prabhu Kumar and M. Joseph Davidson

27. ASTM E407-07 Standard Practice for Microetching Metals and Alloys ASTMI, 100 Barr Harbor Drive, PO Box C700, West Conshohocken, PA 19428 - 2959, United States

28. ASTM E08-04 Standard Test Methods for Tension Testing of Metallic Materials, ASTM International, 100 Barr Harbor Drive, PO Box C700, West Conshohocken, PA 19428 - 2959, United States

29. Chen Y, Liu H, Feng J (2006) Friction stir welding characteristics of different heat-treated-state 2219 aluminum alloy plates. Materials Science Engineering: A 420:21-25. 10.1016/j.msea.2006.01.029

30. Sutton M, Yang B, Reynolds AP, Taylor R (2002) Microstructural studies of friction stir welds in 2024T3 aluminum. Materials Science Engineering: A 323:160-166. 10.1016/S0921-5093(01)01358-2

31. Saleh A, Abass (2018) Effect of heat treatment on the mechanical properties of AA2014 alloy. Contemporary Engineering Sciences 11:3409-3419. 10.12988/ces.2018.87345

32. Devuri V, Cheepu MM, Kumar B, Mahapatra M (2018) Analysing the Friction Stir Welded Joints of AA2219 Al-Cu Alloy in Different Heat-Treated-State. IOP Conference Series Materials Science and Engineering. 330. 012074. 10.1088/1757-899x/330/1/012074

33. Rajendran C, Srinivasan K, Balasubramanian V, Balaji H, Selvaraj P (2016) Influences of post weld heat treatment on tensile strength and microstructure characteristics of friction stir welded butt joints of AA2014-T6 aluminum alloy. Journal of the Mechanical Behavior of Materials 25. 10.1515/jmbm2016-0011

34. Devuri V, Cheepu MM, Rao P, Senthil S Kumaran \& Srinivasan N (2019) Characterization of Microstructure and Mechanical Properties of AA2219-0 and T6 Friction Stir Welds. Materials Science Forum 969:205-210. 10.4028/www.scientific.net/MSF.969.205 
35. Aydin H, Bayram A, Uguz A, Akay S (2009) Tensile properties of friction stir welded joints of 2024 aluminum alloys in different heat-treated-state. Materials Design 30:2211-2221.

10.1016/j.matdes.2008.08.034

36. Al-Dwairi A, Abdelall E, Rivero I (2020) Effect of Pre-welding Heat Treatment on the Mechanical Properties of Friction Stir Welded Al-4 wt.\%Cu Alloys. Metallography, Microstructure, and Analysis. $10.1007 /$ s13632-020-00628-3

37. Xu W, Liu J, Zhu H, Fu L (2013) Influence of welding parameters and tool pin profile on microstructure and mechanical properties along the thickness in a friction stir welded aluminum alloy. Materials Design 47:599-606. 10.1016/j.matdes.2012.12.065

38. Ji S, Meng X, Liu J, Zhang LG, Gao SS (2014) Formation and mechanical properties of stationary shoulder friction stir welded 6005A-T6 aluminum alloy. Materials Design 62:113-117. 10.1016/j.matdes.2014.05.016

39. handbook' ASM, Vol. 6, 'Welding, brazing and soldering'. Ed.: Olson, D. L. et al. Materials Park, OH, ASM International

40. Frigaard $\varnothing$, Grong, $\varnothing \&$ Midling $O$ (2001) A Process Model for Friction Stir Welding of Age Hardening Aluminum Alloys. Metallurgical and Materials Transactions A. 32. 1189-1200. 10.1007/s11661-0010128-4

41. Midling OT, Oosterkamp LD, Bersaas J. Friction stir welding aluminium process and applications. In: Proceedings of the seventh international conference on joints in aluminium, INALCO98; 1998

42. Backlund J, Norlin A, Andersson A. Friction stir welding-weld properties and manufacturing techniques. In: Proceedings of the seventh international conference on joints in aluminium, INALC098; 1998

43. Lee W, Yeon Y-M, Jung S-B (2004) Mechanical Properties Related to Microstructural Variation of 6061 Al Alloy Joints by Friction Stir Welding. Materials Transactions - MATER TRANS 45:1700-1705. 10.2320/matertrans.45.1700

44. Liu H, Zhang H, Pan Q, Yu L (2011) Effect of friction stir welding parameters on microstructural characteristics and mechanical properties of 2219-T6 aluminum alloy joints. International Journal of Material Forming 5. 10.1007/s12289-011-1048-5

45. İpekoğlu G, Erim S, Goren-Kıral B, Çam G (2013) Investigation into the effect of temper condition on friction stir weldability of AA6061 Al-alloy plates. Kovove Materialy 51:155-163. 10.4149/km-20133-155

46. İpekoğlu G, Erim S, Çam G (2014) Effects of temper condition and post weld heat treatment on the microstructure and mechanical properties of friction stir butt-welded AA7075 Al alloy plates. The International Journal of Advanced Manufacturing Technology 70. 10.1007/s00170-013-5255-8

47. Liu H, Fujii H, Maeda M, Nogi K (2003) Heterogeneity of mechanical properties of friction stir welded joints of 1050-H24 aluminum alloy. Journal of Materials Science Letters 22:441-444.

10.1023/A:1022959627794 
48. Rezaei MR, Toroghinejad MR, Ashrafizadeh F (2011) Effects of ARB and ageing processes on mechanical properties and microstructure of 6061 aluminum alloy. Journal of Materials Processing Technology - J Mater Process Technol 211:1184-1190. 10.1016/j.jmatprotec.2011.01.023

\section{Figures}
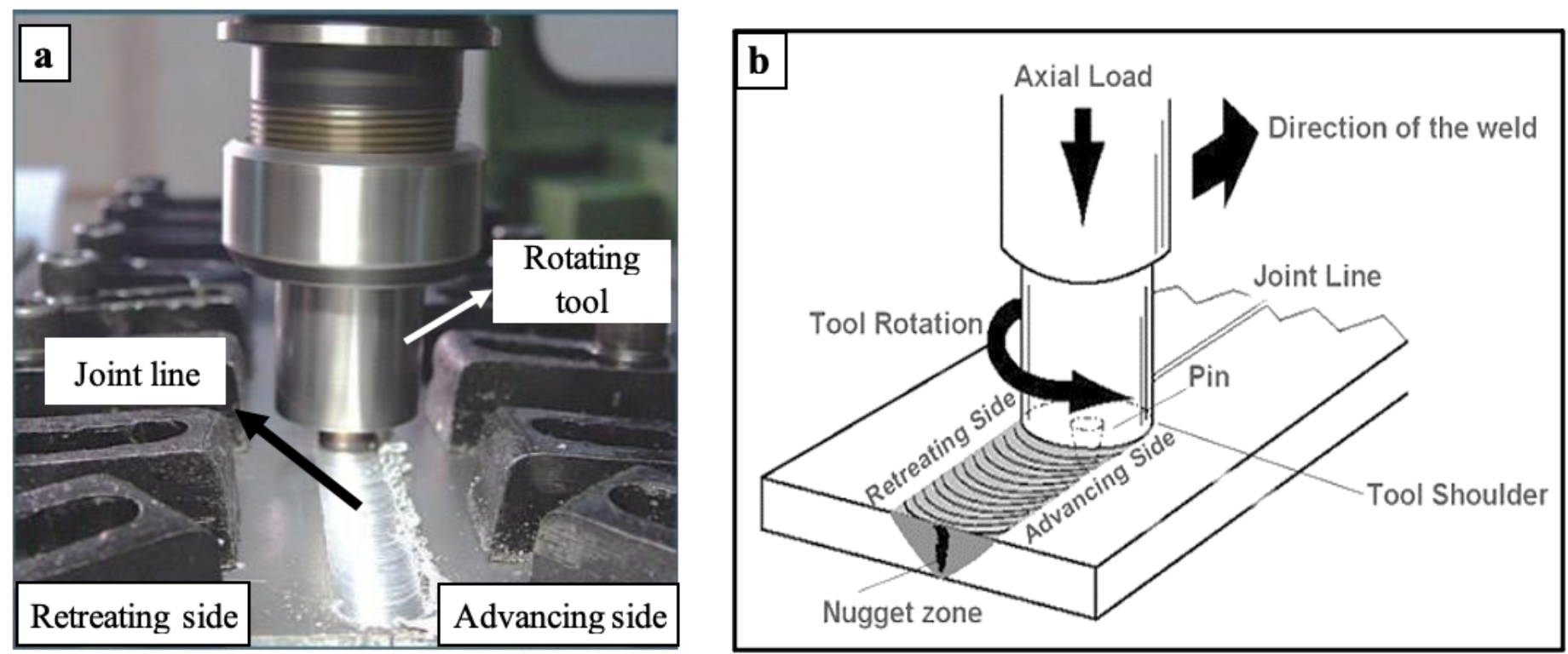

Figure 1

Friction stir welding setup a) physical picture b) schematic diagram
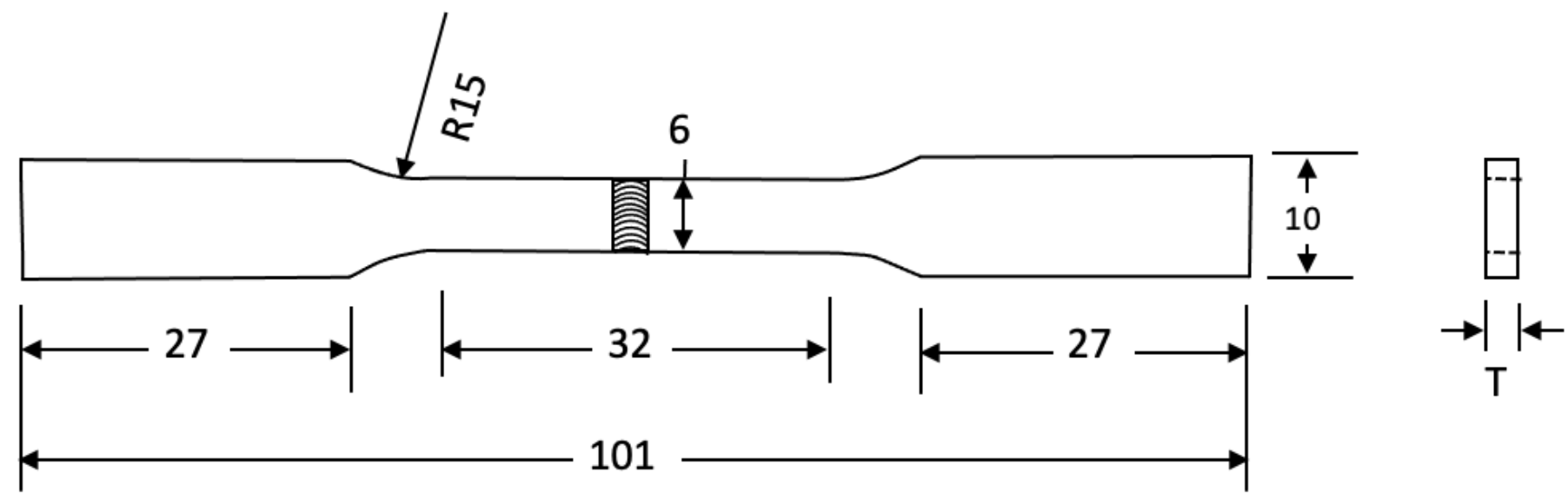

Figure 2

Schematic diagram of the tensile sample 

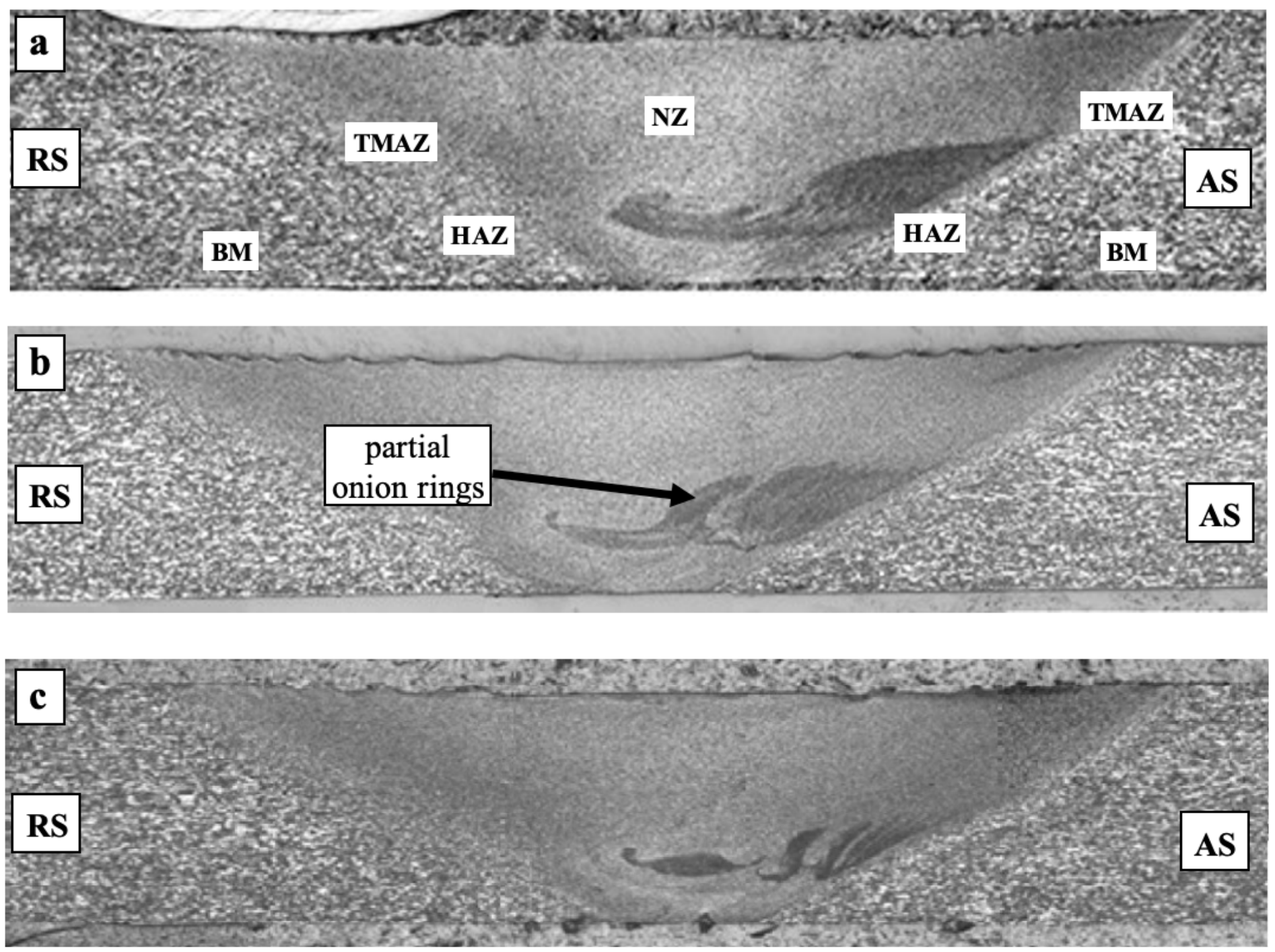

\section{Figure 3}

Macrographs (20x) of transverse sections of 2014-0 samples welded at travel speed of a) $120 \mathrm{~mm} / \mathrm{min}$ b) $200 \mathrm{~mm} / \mathrm{min}$ c) $280 \mathrm{~mm} / \mathrm{min}$ 

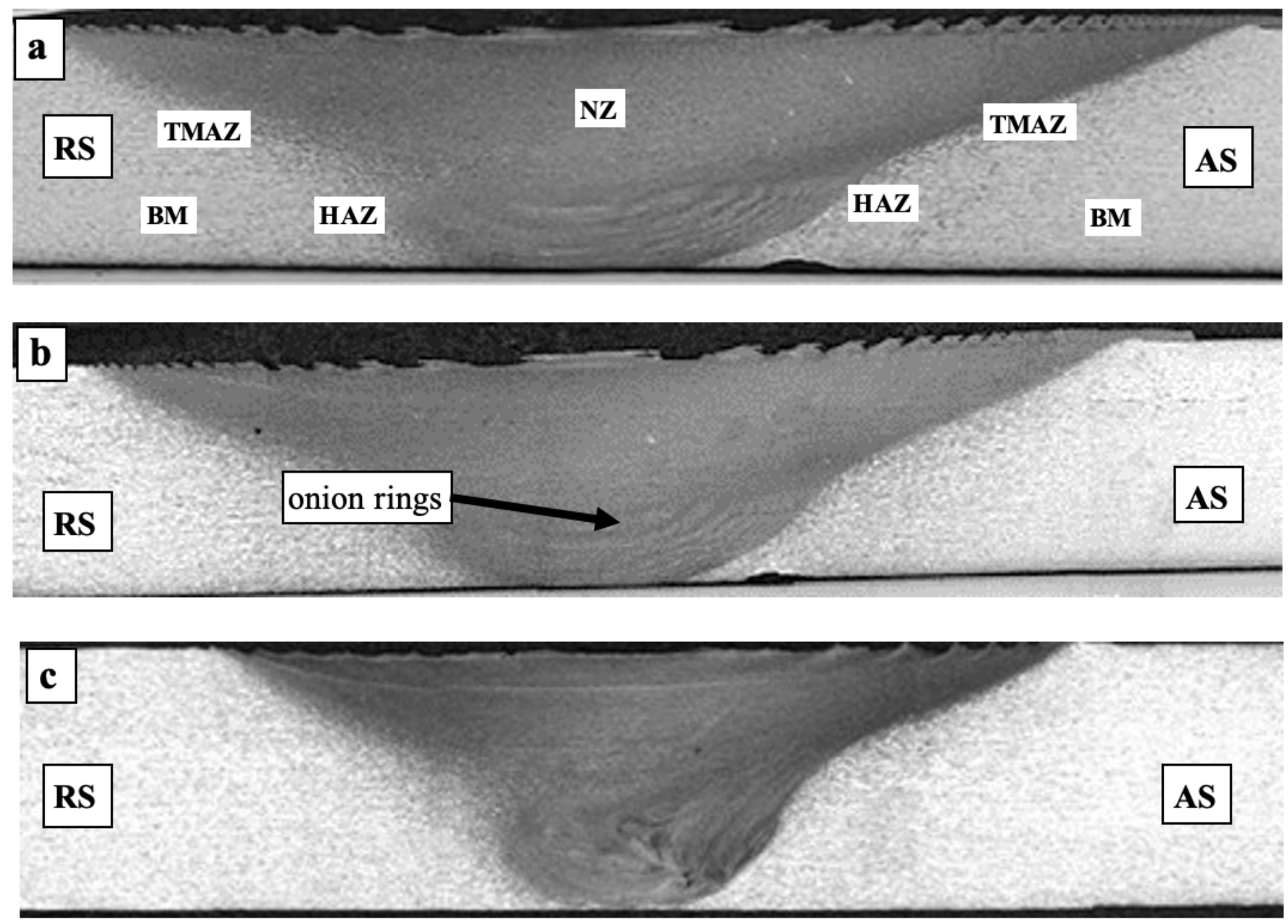

Figure 4

Macrographs (20x) of transverse sections of 2014-T6 samples welded at travel speed of a) $120 \mathrm{~mm} / \mathrm{min}$ b) $200 \mathrm{~mm} / \mathrm{min}$ c) $280 \mathrm{~mm} / \mathrm{min}$
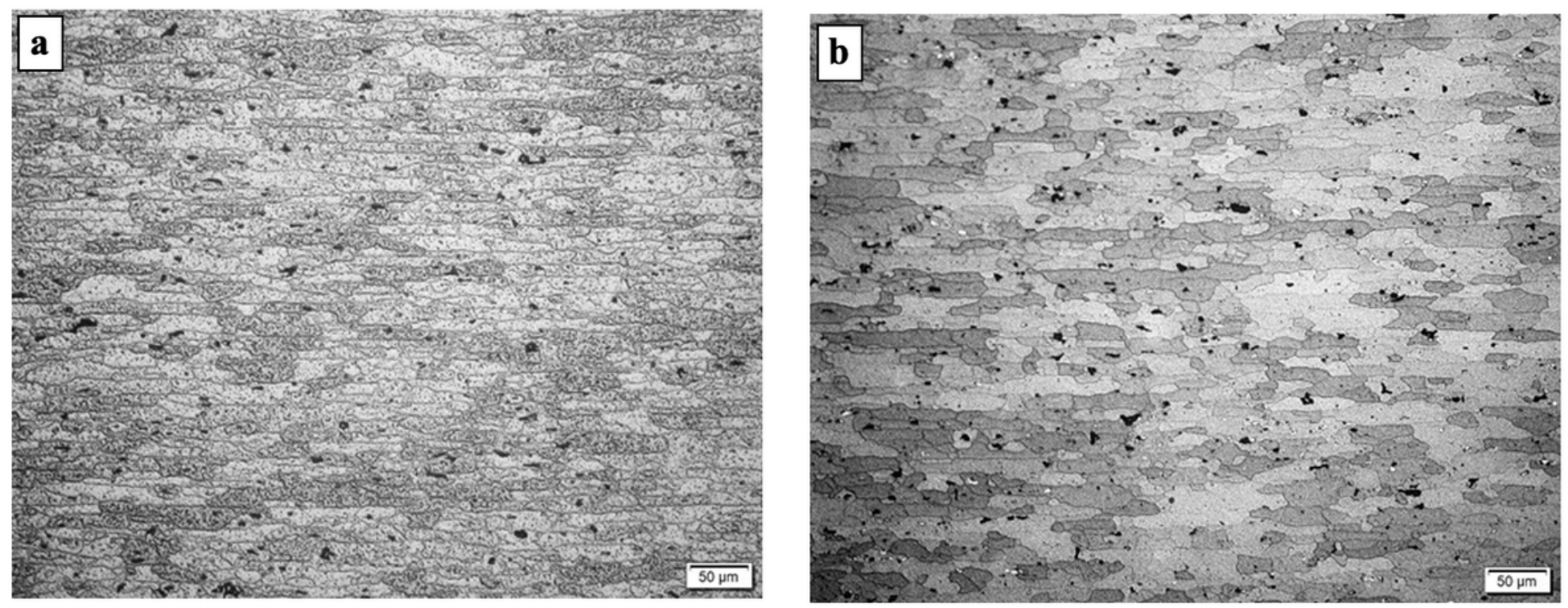


\section{Figure 5}

Optical micrographs of base metals a) 2014-0 b) 2014-T6
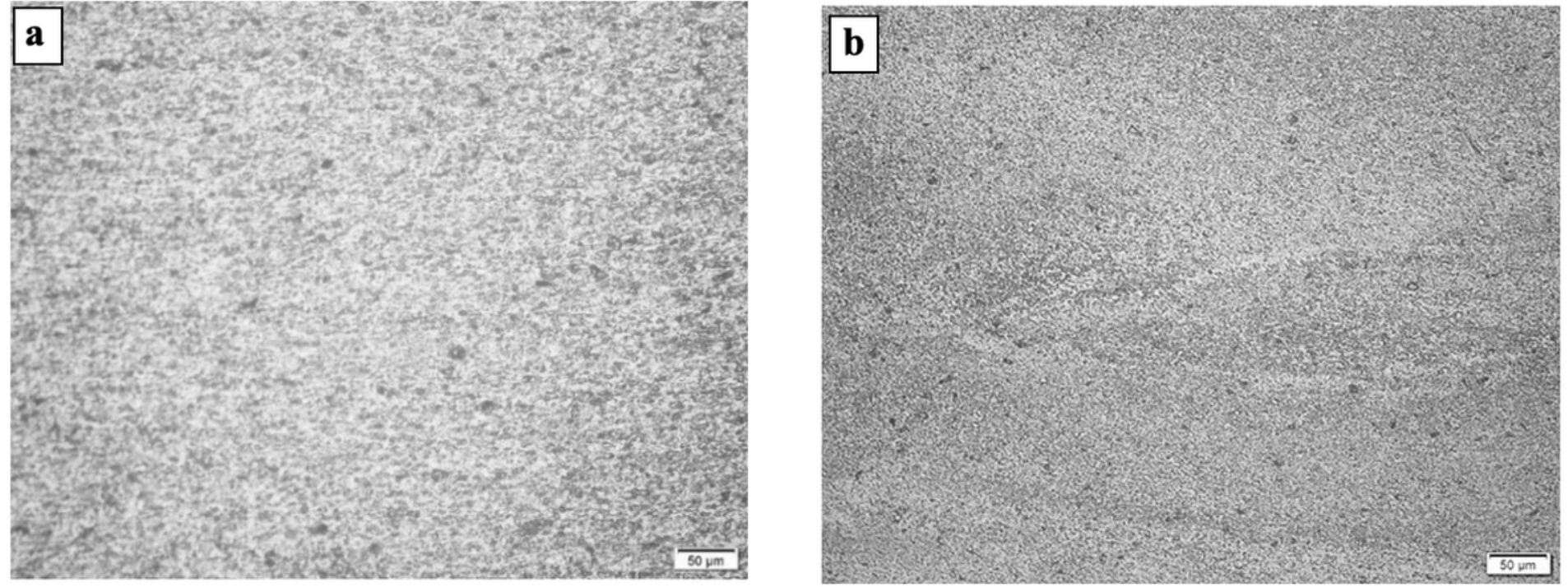

\section{Figure 6}

Optical micrograph of nugget zone welded at travel speed of $200 \mathrm{~mm} / \mathrm{min}$ a) 2014-0 b) 2014-T6
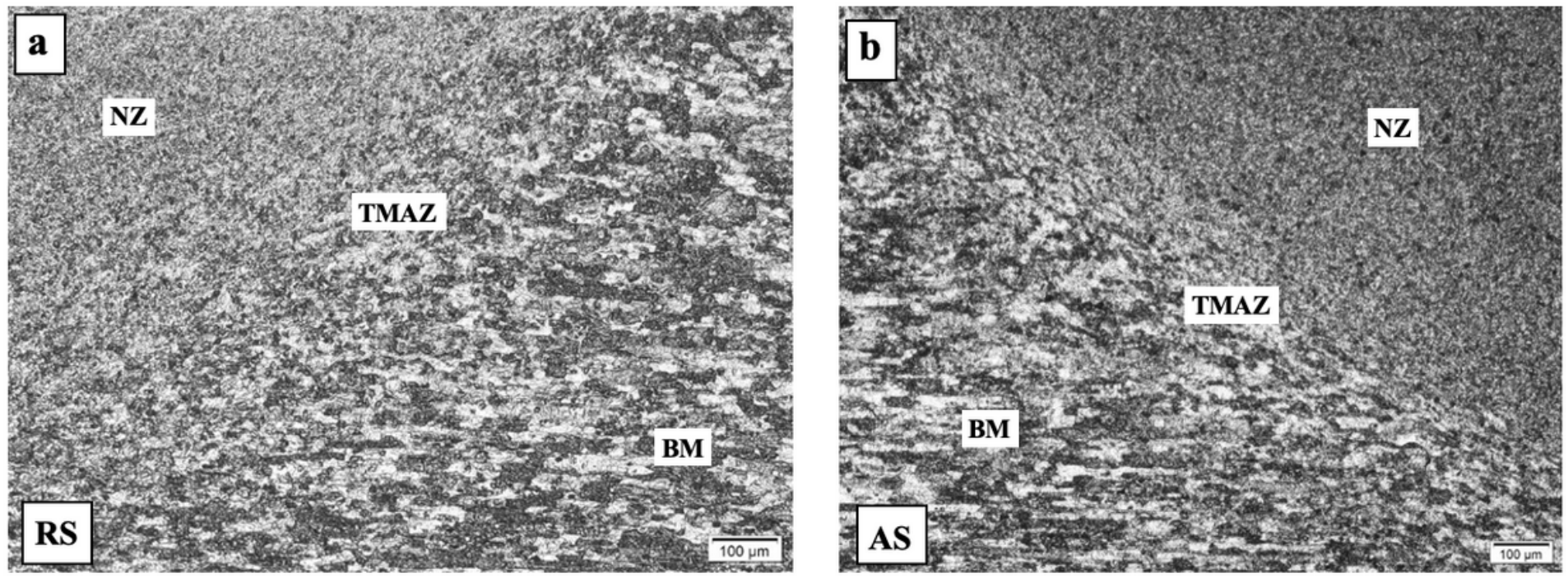

Figure 7

Optical micrograph of the transition zones from NZ to TMAZ in 2014-0 samples welded at travel speed of $120 \mathrm{~mm} / \mathrm{min}$ 

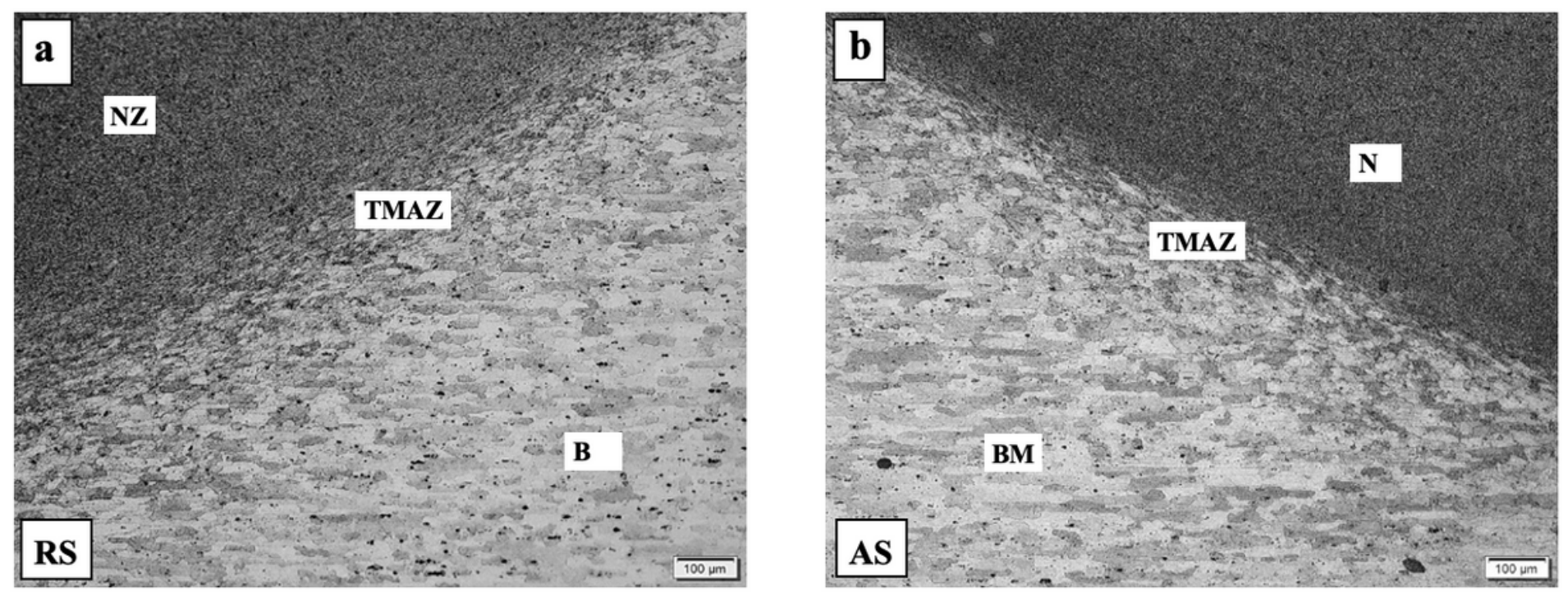

\section{Figure 8}

Optical micrograph of the transition zones from NZ to TMAZ in 2014-T6 samples welded at travel speed of $120 \mathrm{~mm} / \mathrm{min}$
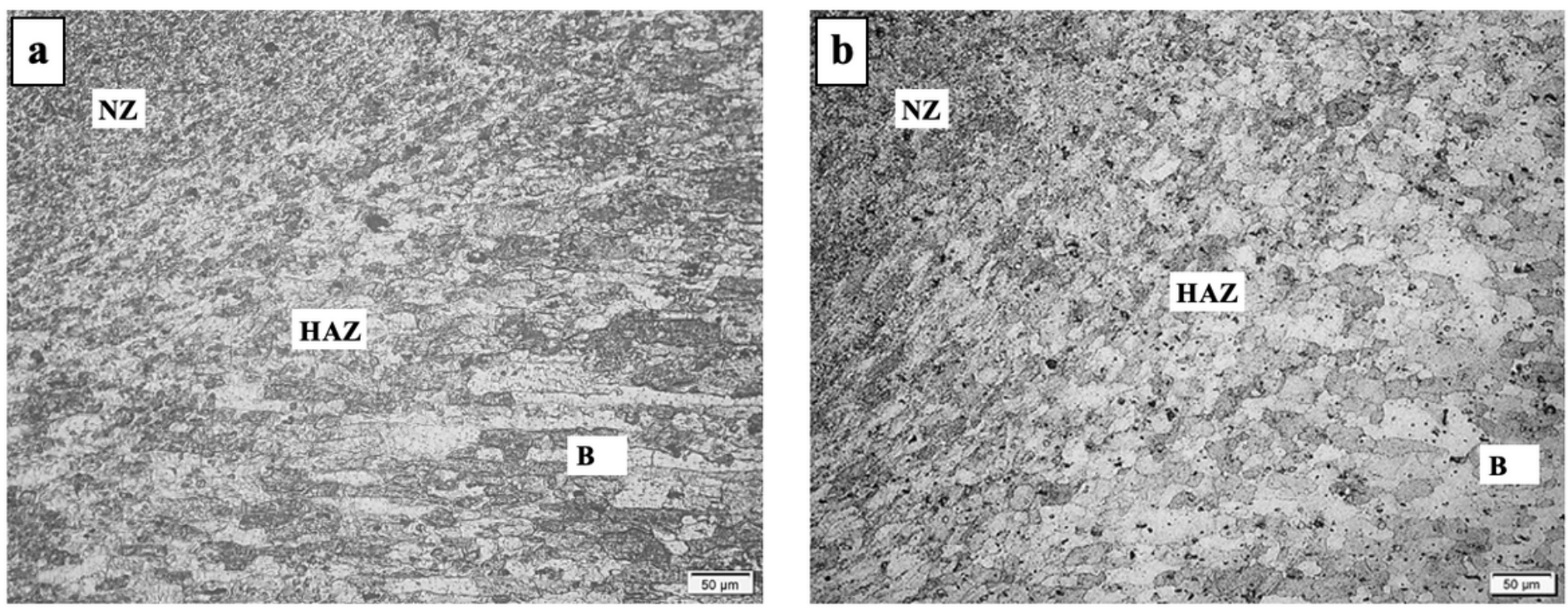

Figure 9

Optical micrograph of the HAZ welded at travel speed of $200 \mathrm{~mm} / \mathrm{min}$ a) 2014-0 b) 2014-T6 


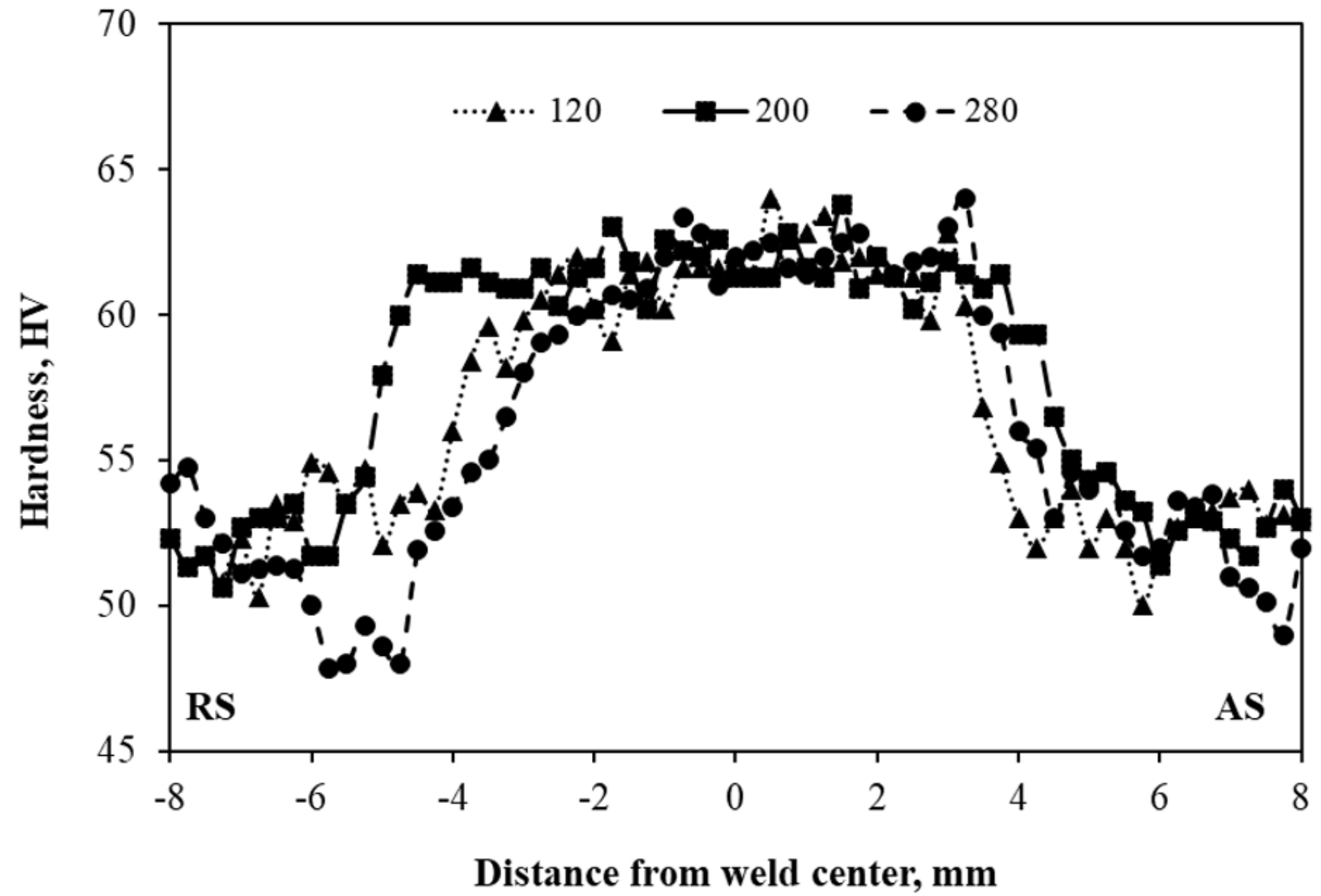

Figure 10

Microhardness profiles across the mid-section of 2014-0 joints, welded at different welding parameters 


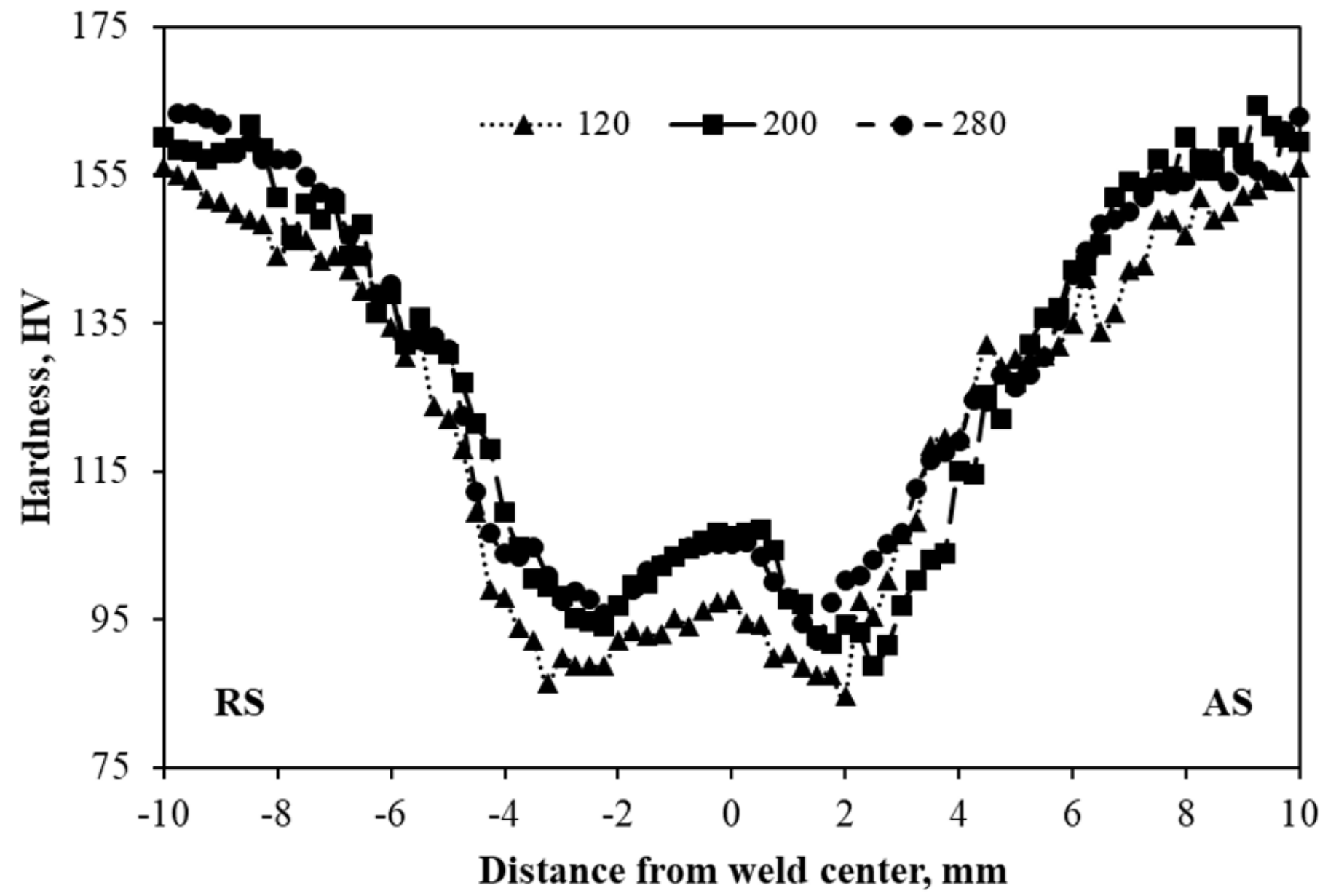

Figure 11

Microhardness profiles across the mid-section of 2014-T6 joints, welded at different welding parameters 


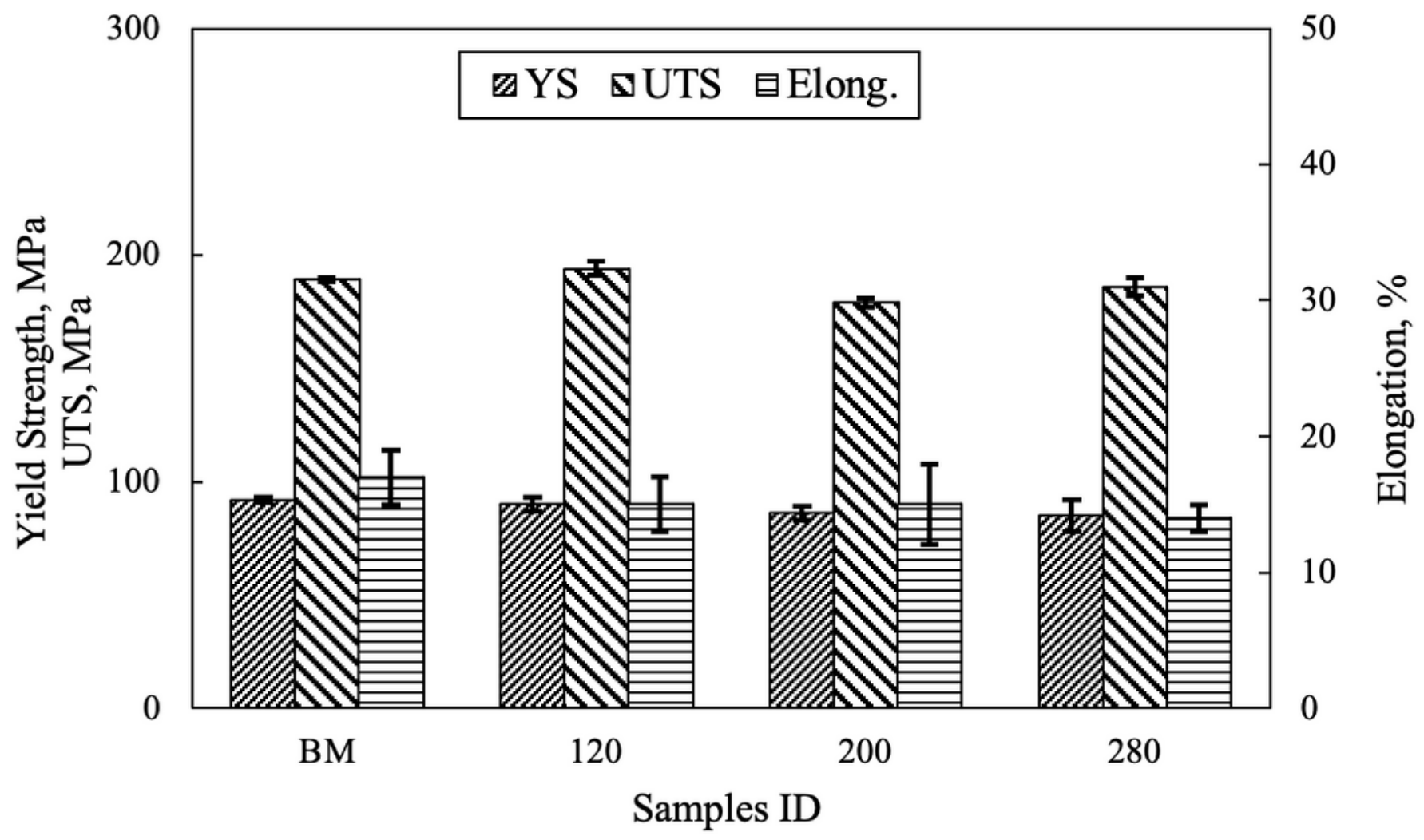

Figure 12

Mechanical properties of 2014-0 joints alongwith BM properties 


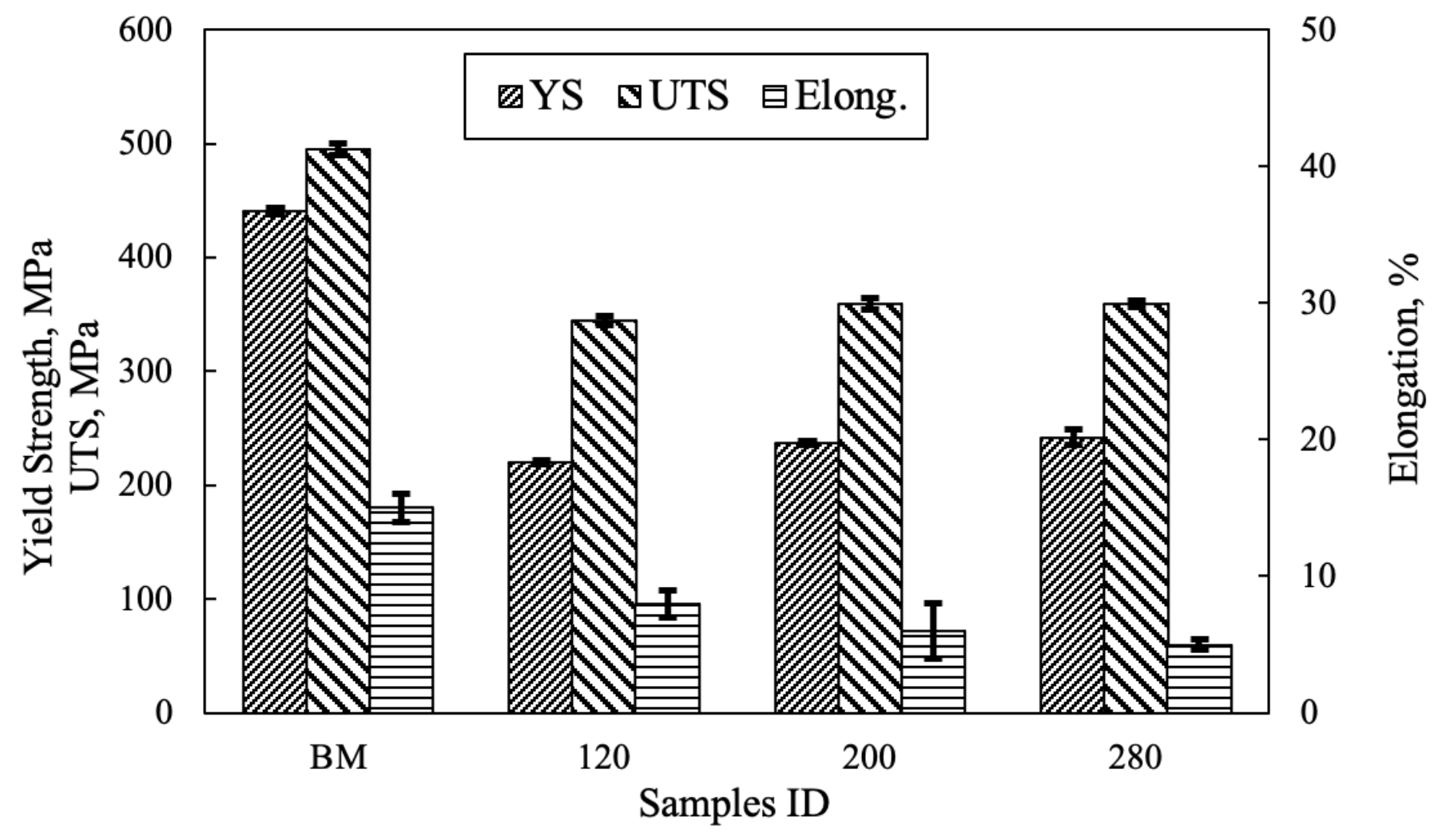

Figure 13

Mechanical properties of 2014-T6 joints alongwith BM properties 


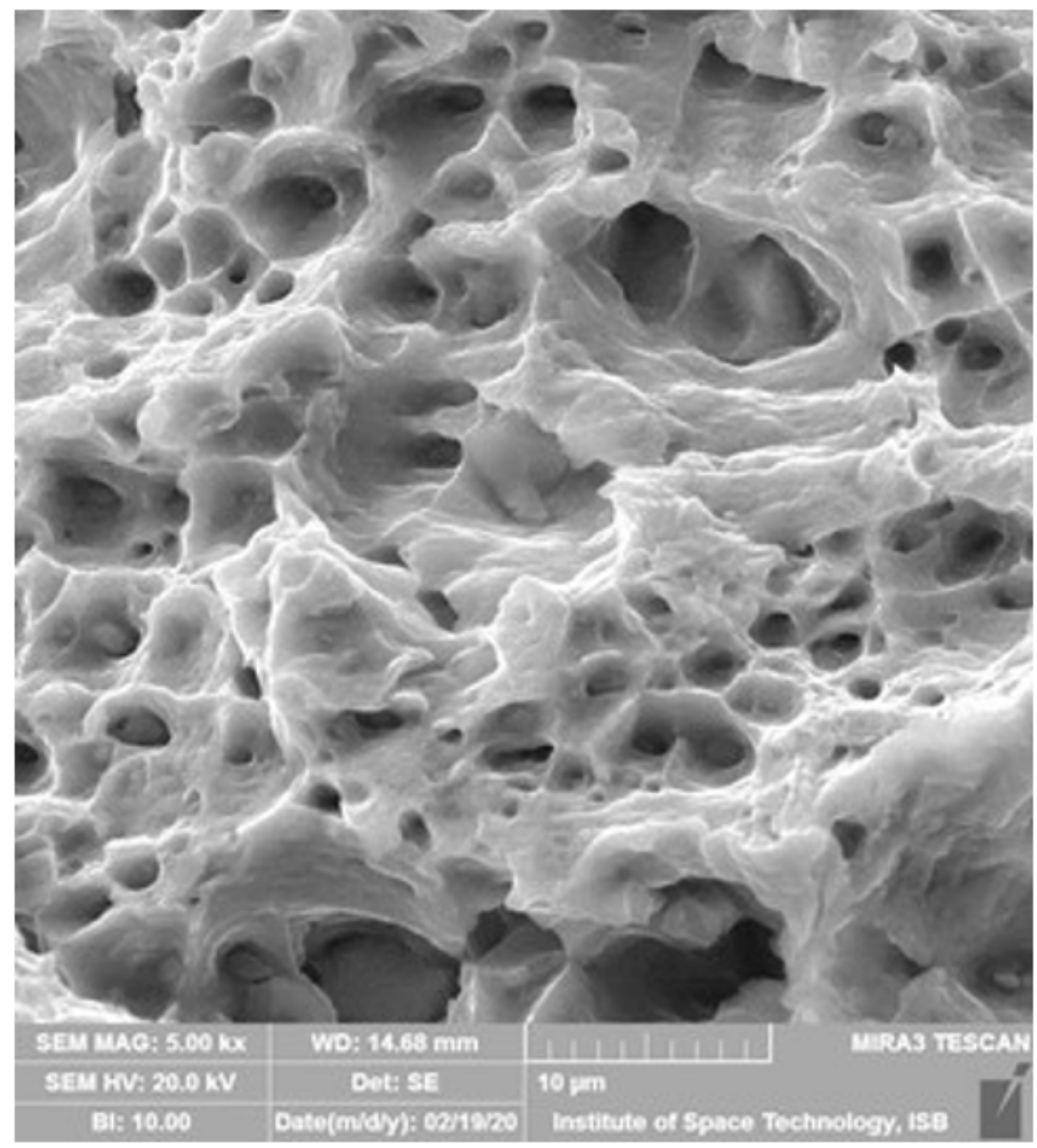

Figure 14

SEM fractograph of 2014-0 sample
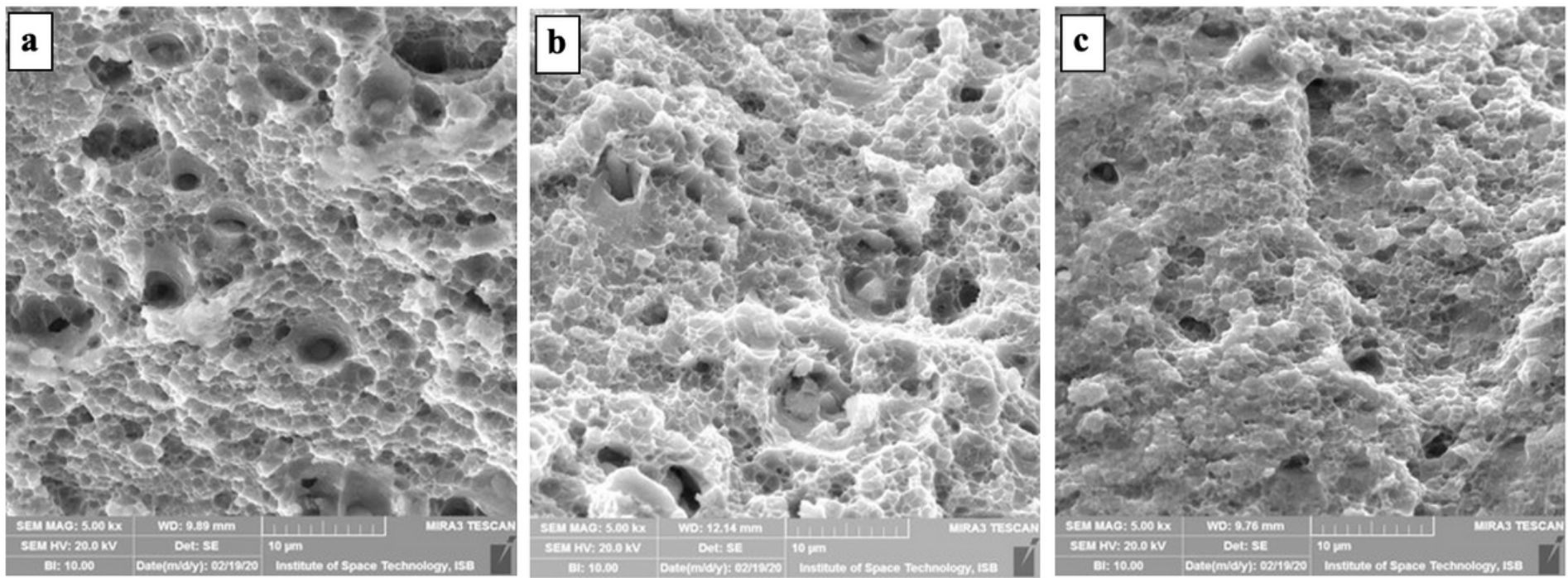
Figure 15

SEM fractograph of 2014-T6 samples welded at a) 120 b) 200 c) 280 